\title{
Prognostic value of myocardial strain and late gadolinium enhancement on cardiovascular magnetic resonance imaging in patients with idiopathic dilated cardiomyopathy with moderate to severely reduced ejection fraction
}

Seung-Hoon $\mathrm{Pi}^{1 \dagger}$, Sung Mok Kim² ${ }^{2 \dagger}$, Jin-Oh Choi ${ }^{1 *}$ (D), Eun Kyoung Kim', Sung-A Chang ${ }^{1}$, Yeon Hyeon Choe ${ }^{2}$, Sang-Chol Lee ${ }^{1}$ and Eun-Seok Jeon ${ }^{1}$

\begin{abstract}
Background: It has been reported that left ventricular (LV) myocardial strain and late gadolinium enhancement (LGE) on cardiovascular magnetic resonance (CMR) imaging have prognostic value in patients with heart failure (HF). However, previous studies included patients with various systolic functions. This study aimed to investigate the prognostic value of LV myocardial strain and LGE on CMR imaging in patients with idiopathic dilated cardiomyopathy (DCM) with reduced ejection fraction (EF < 40\%).

Methods: From a prospectively followed cohort who underwent CMR between November 2008 and December 2015, subjects with LV EF $<40 \%$ and a diagnosis of idiopathic DCM were eligible for this study. The CMR images were analyzed for LV and right ventricular (RV) function, presence and extent of LGE, and LV myocardial strain. The primary outcome was a composite of all-cause death and heart transplantation. The secondary outcome was hospitalization for HF.
\end{abstract}

Results: A total of 172 patients were included, in whom mean LV EF was $23.7 \pm 7.9 \%$ (EF 30-40\% $n=47$; EF $<30 \% n=$ 125). During a median follow-up of 47 months, the primary outcome occurred in 43 patients (16 heart transplantations, 29 all-cause deaths), and there were 41 hospitalizations for HF. Univariate Cox proportional hazard regression analysis showed that mean arterial pressure, serum sodium concentration, log of plasma NT-proBNP level, and presence of LGE (HR 2.277, 95\% Cl: 1.221-4.246) were significantly associated with the primary outcome. However, LV strain had no significant association (HR 1.048, 95\% Cl: 0.945-1.163). Multivariable analysis showed that presence of LGE (HR 4.73, 95\% Cl: $1.11-20.12$ ) and serum sodium (HR 0.823 , 95\% Cl: 0.762-0.887) were independently associated with the primary outcome.

(Continued on next page)

\footnotetext{
* Correspondence: choijean5@gmail.com

†Seung-Hoon Pi and Sung Mok Kim contributed equally to this work.

'Department of Internal Medicine, Heart Vascular Stroke Institute, Samsung

Medical Center, Sungkyunkwan University School of Medicine, 81 Irwon-ro,

Gangnam-gu, Seoul 06351, Republic of Korea

Full list of author information is available at the end of the article
}

(c) The Author(s). 2018 Open Access This article is distributed under the terms of the Creative Commons Attribution 4.0 International License (http://creativecommons.org/licenses/by/4.0/), which permits unrestricted use, distribution, and reproduction in any medium, provided you give appropriate credit to the original author(s) and the source, provide a link to the Creative Commons license, and indicate if changes were made. The Creative Commons Public Domain Dedication waiver (http://creativecommons.org/publicdomain/zero/1.0/) applies to the data made available in this article, unless otherwise stated. 
(Continued from previous page)

Conclusions: LGE in CMR imaging was a good predictor of adverse outcomes for patients with idiopathic DCM and reduced EF. Identification of LGE could thus improve risk stratification in high-risk patients. LV strain had no significant prognostic value in patients with moderate to severe systolic dysfunction.

Keywords: Cardiovascular magnetic resonance imaging, Myocardial strain, Prognosis, Late gadolinium enhancement, Idiopathic dilated cardiomyopathy

\section{Background}

Idiopathic dilated cardiomyopathy (DCM) accounts for a substantial proportion of heart failure (HF) cases [1, 2]. It is associated with significant morbidity and mortality due to HF and sudden cardiac death [3-5]. Although several factors in patients with HF [6-15] are associated with an adverse prognosis, risk stratification remains challenging. Therefore, better tools are needed for risk stratification in order to guide individualized treatment strategies and patient surveillance.

Cardiovascular magnetic resonance (CMR) imaging has become recognized as the gold standard for assessment of cardiac function and mass $[16,17]$, and it can be used to distinguish the etiology of $\operatorname{HF}[18,19]$. Additionally, it has been reported that the appearance of late gadolinium enhancement (LGE) [20-23] and left ventricular (LV) myocardial strain in CMR imaging [24] have prognostic value in patients with non-ischemic DCM. However, those studies included patients with various systolic functions.

Therefore, we investigated the prognostic value of LV myocardial strain and LGE in the CMR images of patients with idiopathic DCM with reduced ejection fraction (EF).

\section{Methods}

\section{Study population}

From a prospectively followed cohort who underwent CMR at Samsung Medical Center, Seoul, Korea, between November 2008 and December 2015, subjects whose LV EF was less than $40 \%$ were eligible for this study ( $n=$ 441). Medical records were reviewed, and those from patients with an LV EF less than 40\% who had been diagnosed previously with idiopathic DCM were evaluated. The diagnosis of DCM was made according to the criteria of the World Health Organization/International Society and Federation of Cardiology [25]. Patients had to exhibit dilatation and impaired contraction of the LV or both ventricles in the absence of valvular disease, hypertensive heart disease, and congenital abnormalities. The possibility of ischemic heart disease was excluded by invasive $\mathrm{x}$-ray coronary angiography or non-invasive testing such as coronary computed tomography angiography (defined as $\geq 50 \%$ luminal stenosis) [24] or CMR itself (subendocardial or transmural pattern of LGE suggestive of previous myocardial infarction) [18], according to each physician's clinical decision.

Of all potentially eligible patients $(n=441)$, pediatric patients $(n=20)$ and 154 patients with ischemic heart disease, constrictive pericarditis, tachycardia-induced cardiomyopathy, cardiomyopathy due to endocrine dysfunction, cardiomyopathy due to infection with the human immunodeficiency virus, stress induced cardiomyopathy, infiltrative myocardial disease, hypertensive heart disease, cardiomyopathy due to systemic autoimmune disease, alcoholic cardiomyopathy, cardiomyopathy related to chemotherapeutic agents, restrictive cardiomyopathy, significant organic valvular disease, or hypertrophic cardiomyopathy were excluded. Of 267 patients with a diagnosis of idiopathic DCM, we excluded 95 because their CMR images were inappropriate for strain measurement, resulting in a final sample size of 172 patients (Fig. 1). This study and all of its analyses were approved by the Institutional Review Board of Samsung Medical Center which waived written informed consent.

\section{CMR image acquisition}

All subjects underwent CMR in a $1.5 \mathrm{~T}$ scanner (Magnetom Avanto, Syngo MR B17 version; Siemens Healthineers, Erlangen, Germany) with a 32-channel phased-array receiver coil. CMR scans consisted of localizing images (axial, coronal, and sagittal), cine scans, and LGE scans. After localization, cine images of the LV were acquired using a balanced steady-state free-precession sequence in the 4-, 3-, and 2-chamber and short axis views to obtain contiguous slices that included the entire $\mathrm{LV}$, with a $6-\mathrm{mm}$ slice thickness and 4-mm intersection gaps. At each level, cine images were composed of 30 phases per cardiac cycle. Cine images were obtained during multiple breath-holds. LGE imaging was acquired using a phase-sensitive inversion recovery technique $10 \mathrm{~min}$ after injection of $0.2 \mathrm{mmol} / \mathrm{kg}$ gadobutrol (Gadovist; Bayer Healthcare, Berlin, Germany) at a rate of $3 \mathrm{ml} /$ sec, followed by a $30-\mathrm{ml}$ saline flush. Contiguous short-axis image acquisition of 10-12 slices was used, with $6 \mathrm{~mm}$ thickness and a 4-mm interslice gap. Inversion delay times were typically $280-360 \mathrm{msec}$. 


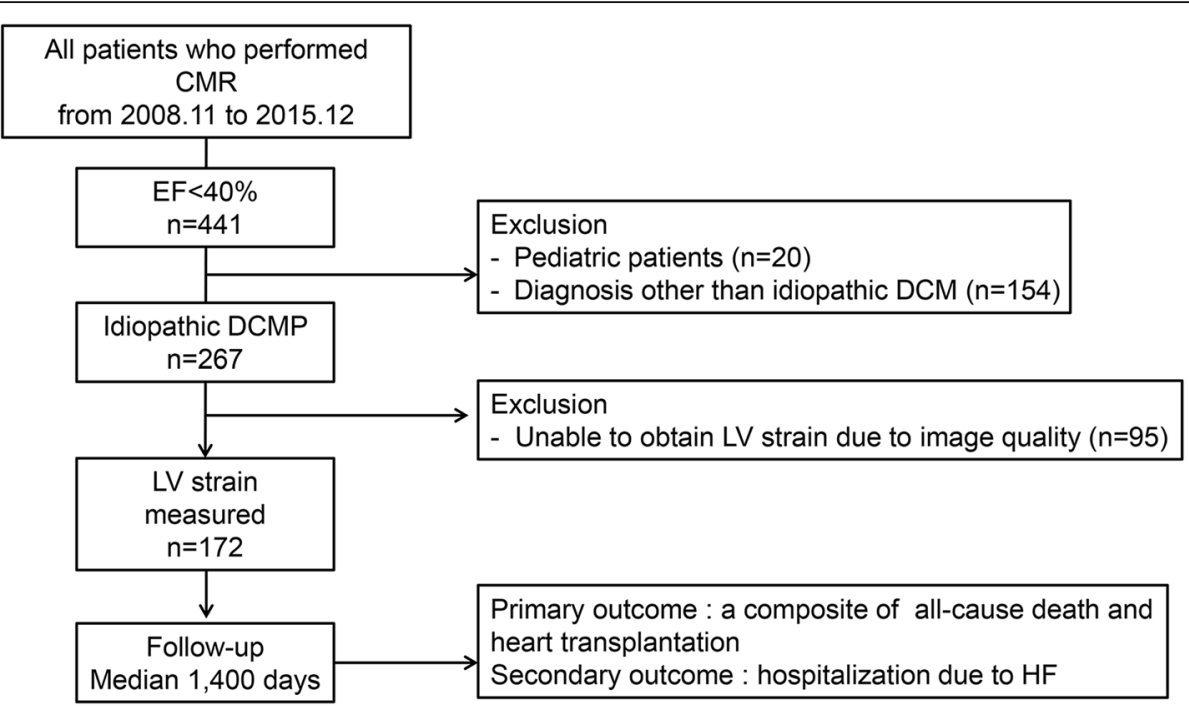

Fig. 1 Study Design and Population. Abbreviations: CMR, cardiovascular magnetic resonance; DCM, dilated cardiomyopathy; EF, ejection fraction; HIV, human immunodeficiency virus; LV, left ventricular

\section{LV myocardial strain analysis}

CMR tissue tracking analyses were performed using commercially available software (cvi42 version 5, Circle Cardiovascular Imaging Inc., Calgary, Alberta, Canada). Two-, three-, and four-chamber and short axis images were uploaded into the software, which reconstructs a $3 \mathrm{D}$ model that we used to analyze 2D-radial, circumferential, and longitudinal LV strain. The preferred images were loaded into the analysis/viewer frame of the software and analyzed in random order by two investigators (SHP with 1 year and JWH with 3 years of CMR experience) who were independently blinded to the clinical findings. Tissue tracking analysis was manually performed by drawing the endo- and epicardial surfaces in end-diastolic phase (reference phase) using short axis stacked slices (Fig. 2). A short axis reference point was manually delineated at the right ventricle (RV) upper and lower septal insertion of the LV for regional and global analysis of strain and the generation of polar map views. Next, the software automatically drew the contour and traced its myocardium voxel points throughout the remainder of the cardiac cycle. The algorithm

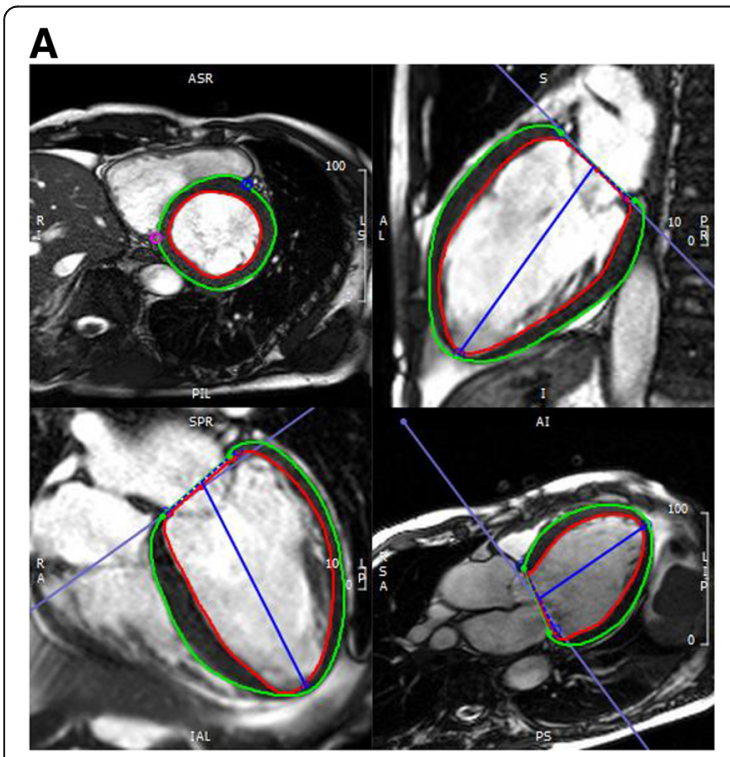

\section{B}

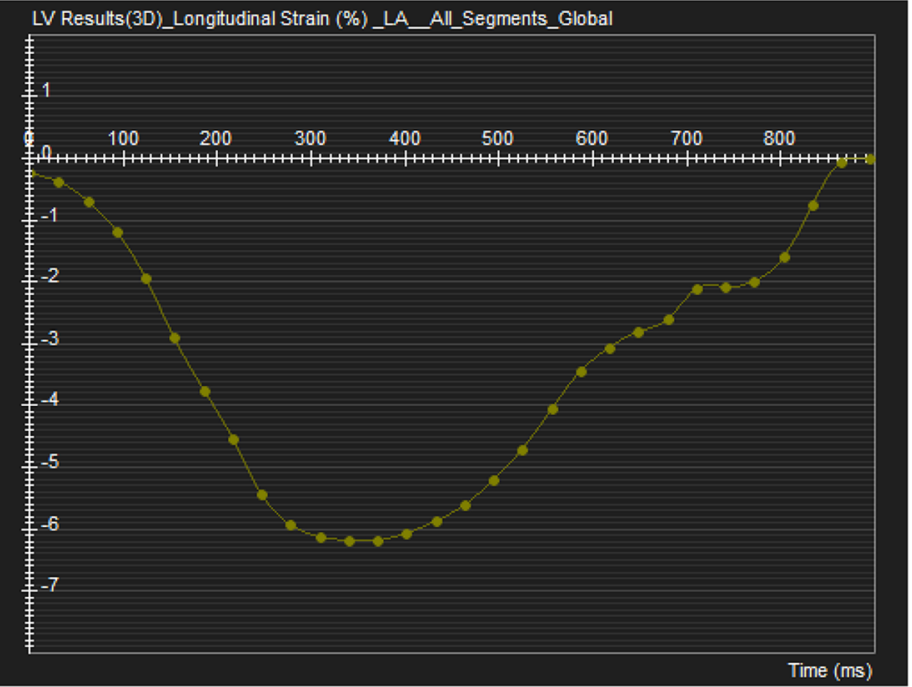

Fig. 2 Strain Analysis by Feature Tracking. a The endocardial and epicardial borders were traced manually at end-diastolic phase. b Global peak longitudinal strain curve by feature tracking. Abbreviations: LA, left atrial; LV, left ventricular 
determined and depicted the left borders of the LV myocardium in the following phases of a cardiac cycle based on the endo- and epicardial contours of the reference phase. The software automatically performed $2 \mathrm{D}$ strain analyses of all slices.

The routine cine images of 172 patients included for strain analysis consist of 30 images per cardiac cycle. Those images were acquired using retrospective (electrocardiogram (ECG)-gated, multi-breathhold technique. The patients excluded from the analyses for strain underwent different scan technique using single-breathhold method for obtaining cine images because of arrhythmia or lack of breath-hold. Because of this, the number of image frames was variable $(10 \sim 24$ images), so the temporal resolution was also different and we could not perform the analysis of LV strain.

\section{LGE measurement}

The presence and extent of LGE were evaluated by one observer experienced in LGE-CMR, who was blinded to clinical data and outcomes. For quantification of fibrosis, LGE was defined as areas with a signal intensity $>6 \mathrm{SD}$ $[26,27]$ above the mean signal intensity of remote myocardium in the same short-axis slice using commercial software (CAAS MRV version 1.0, Pie Medical Imaging B.V., Maastricht, The Netherlands). Areas are expressed as mass and percentage of myocardial mass.

\section{Follow-up and endpoints}

All patients were followed by medical record review. Vital status was cross-checked in all of the patients using National Insurance data from the Korean government, which contain unique identifiers for the patients [28]. The median follow-up duration was 1400 days (Q1-Q3: 770 to 2210 days). The primary outcome was a composite of all-cause death and heart transplantation. The secondary outcome was first hospitalization due to HF.

\section{Statistical analysis}

Categorical variables are presented as numbers and relative frequencies (percentages), and continuous variables as means and standard deviations or medians with interquartile ranges $(\mathrm{Q} 1-\mathrm{Q} 3)$, according to their distribution, which was checked using the Kolmogorov-Smirnov test. Categorical variables were compared using chi-square tests, and continuous variables were compared using Student's t-test or analysis of variance. Cumulative events rates were calculated based on Kaplan-Meier censoring estimates, and the log-rank test was used to compare survival curves. We proceeded with multiple Cox regression model to understand the variability in time to event in the two primary endpoints. Based on univariate analysis, all demographic or clinical variables with $p$-values $<0.2$ were initially considered to enter the model. Then, we eliminated insignificant variables $(p>0.05)$ one by one to obtain a robust and parsimonious model for prediction. We verified the model assumption of proportional hazards via Schoenfeld residuals. When the assumption fails, we attempted accommodating time-dependent covariates and stratified analyses. As a measure of goodness of the prediction model, we obtained the Harrel's c-index. Pearson correlation coefficient was calculated to assess the correlation between LVEF and LV myocardial strains. Inter- and intra-observer variabilities for strain values were assessed by the repeated analysis of 30 randomly selected patients. Statistical analyses were performed using SAS version 9.3 (SAS Institute, Cary, North Carolina, USA), and SPSS (version 19.0, International Business Machines, Armonk, New York, USA). P-values < 0.05 (2-sided) were considered statistically significant.

\section{Results \\ Baseline characteristics}

The baseline clinical characteristics and CMR variables of all 172 patients are summarized in Tables 1 and 2 . Also these data of those who were excluded from and included in the strain analysis was presented in the Additional file 1: Tables S1 and S2. There was no significant difference between 95 excluded and 172 included patients except gender, presence of LBBB, LV myocardial mass. There was no difference in the presence of LGE between the two groups. Mean LV EF of the study subjects was $23.7 \pm 7.9 \%$ (EF $30-40 \% n=47$; $\mathrm{EF}<30 \% n=$ $125)$ and LGE was observed in $66(38.2 \%)$ patients. The Pearson correlation coefficients between LV EF and GLS, GCS, and GRS were $-0.733(P<0.01),-0.780(P<$ $0.01)$, and $0.739(P<0.01)$.

\section{Outcomes}

During the follow-up period, the primary outcome occurred in 43 patients (16 heart transplantations, 29 all-cause deaths), and there were 41 hospitalizations for HF. Between patients with and without the primary outcome, significant differences were observed in terms of mean arterial pressure (MAP), serum sodium $(\mathrm{sNa}), \log$ transformed NT-proBNP $[\ln (\mathrm{NT}-$ proBNP)$]$, and presence of LGE. Regarding LV myocardial strain, none of the systolic strain parameters differed significantly between groups.

\section{Survival analysis}

By univariate analysis, the following clinical parameters were predictors of the primary outcome: presence of LGE, MAP, history of cerebrovascular accident, $\mathrm{Na}$, $\ln (\mathrm{NT}$-proBNP), RV end-diastolic volume (EDV), and RV end-systolic volume (ESV). The presence of LGE, 
Table 1 Baseline characteristics and CMR parameters for patients with and without the primary outcome

\begin{tabular}{|c|c|c|c|c|}
\hline Parameters & All patients $(n=172)$ & $\begin{array}{l}\text { Patients without the primary } \\
\text { outcome }(n=129)\end{array}$ & $\begin{array}{l}\text { Patients with the primary } \\
\text { outcome }(n=43)\end{array}$ & $P$ value \\
\hline Age (years) & $56.4 \pm 14.3$ & $57.0 \pm 14.6$ & $54.8 \pm 13.5$ & 0.398 \\
\hline Male gender, n (\%) & $116(67.4)$ & $85(65.9)$ & $31(72.1)$ & 0.452 \\
\hline Mean arterial pressure $(\mathrm{mmHg})$ & $84 \pm 13$ & $86 \pm 13$ & $80 \pm 12$ & 0.015 \\
\hline Hypertension, n (\%) & $58(33.7)$ & $44(34.1)$ & $14(32.6)$ & 0.852 \\
\hline Diabetes mellitus, n (\%) & $36(20.9)$ & $25(19.4)$ & $11(25.6)$ & 0.387 \\
\hline Dyslipidemia, n (\%) & $11(6.4)$ & $8(6.2)$ & $3(7.0)$ & 0.857 \\
\hline Current smoker, n (\%) & $49(28.5)$ & $37(28.7)$ & $12(27.9)$ & 0.734 \\
\hline Chronic kidney disease $^{a}, \mathrm{n}(\%)$ & $31(18.0)$ & $21(16.3)$ & $10(23.3)$ & 0.303 \\
\hline Previous CVA, n (\%) & $4(2.3)$ & $1(0.8)$ & $3(7.0)$ & 0.049 \\
\hline Body mass index $\left(\mathrm{kg} / \mathrm{m}^{2}\right)$ & $24.0 \pm 4.5$ & $24.2 \pm 4.5$ & $23.5 \pm 4.4$ & 0.347 \\
\hline \multicolumn{5}{|l|}{ ECG at baseline } \\
\hline Heart rate (bpm) & $83 \pm 20$ & $84 \pm 19$ & $83 \pm 22$ & 0.883 \\
\hline Left bundle-branch block, n (\%) & $31(18.0)$ & $23(17.8)$ & $8(19.0)$ & 0.859 \\
\hline QRS duration (ms) & $113 \pm 29$ & $112 \pm 30$ & $117 \pm 29$ & 0.305 \\
\hline \multicolumn{5}{|l|}{ Laboratory data } \\
\hline Serum creatinine (mg/dl) & $0.97 \pm 0.27$ & $0.96 \pm 0.25$ & $1.01 \pm 0.31$ & 0.247 \\
\hline $\mathrm{Na}(\mathrm{mmol} / \mathrm{l})$ & $139.6 \pm 3.3$ & $140.2 \pm 2.8$ & $137.6 \pm 3.8$ & $<0.001$ \\
\hline In(NT-proBNP) (pg/ml) & $7.22 \pm 1.27$ & $7.08 \pm 1.29$ & $7.60 \pm 1.16$ & 0.022 \\
\hline \multicolumn{5}{|l|}{ Cardiac medications } \\
\hline Beta-blockers, n (\%) & $120(69.8)$ & $87(67.4)$ & $33(76.7)$ & 0.250 \\
\hline ACE-inhibitors/ARB, n(\%) & $134(77.9)$ & $104(80.6)$ & $39(90.7)$ & 0.126 \\
\hline Spironolactone, n (\%) & $101(58.7)$ & $74(57.4)$ & $27(62.8)$ & 0.531 \\
\hline Diuretics, n (\%) & $125(72.7)$ & $93(72.1)$ & $32(74.4)$ & 0.767 \\
\hline Digoxin, n (\%) & $33(19.2)$ & $21(16.3)$ & $12(27.9)$ & 0.094 \\
\hline
\end{tabular}

Primary outcome: all-cause death, heart transplantation during follow-up. Values are mean $\pm \mathrm{SD}, \mathrm{n}(\%)$

${ }^{a}$ Chronic kidney disease was defined as eGFR $<60 \mathrm{ml} / \mathrm{min} / 1.73 \mathrm{~m}^{2}$, calculated using the 4-component MDRD study equation

Abbreviations: $A C E$ angiotensin-converting-enzyme, $A R B$ angiotensin II receptor blockers, BNP B-type natriuretic peptide, CVA cerebrovascular accident

ECG electrocardiography

MAP, sNa, ln(NT-proBNP), LV ESV, RV EF, RV ESV, and LV mass were all predictors of the secondary outcome. LV myocardial strain had no significant association with either the primary or secondary outcome (Table 3). Kaplan-Meier curves for the clinical outcomes according to presence of LGE and global longitudinal strain (GLS) are shown in Fig. 3. In Fig. 3c, d, patients were divided into two groups by the median GLS of the total population $(-6.8 \%)$.

Multivariable analysis showed that presence of LGE and $\mathrm{sNa}$ were independently associated with the primary outcome and presence of LGE, sNa, myocardial mass and $\ln (\mathrm{NT}$-proBNP) were independent predictors for secondary outcome. However, the effect of LGE did not satisfy the proportional hazard assumption for the primary outcome, and as stated in the Statistical methods section, we accommodate the LGE effects as time-dependent. The best model indicated that the effect of LGE was significant and dramatically apparent after about 6 months (Table 4).

\section{Reliability}

Intra- and inter-observer reliability values were excellent. Intra- and inter-observer intraclass correlation coefficients were 0.993 (95\% CI: $0.985-0.997)$ and 0.944 (95\% CI: 0.875-0.975), respectively, for GLS; 0.993 (95\% CI: $0.985-0.997)$ and 0.962 (95\% CI: 0.915-0.983), respectively, for global circumferential strain (GCS); and 0.986 (95\% CI: 0.971-0.993) and 0.955 (95\% CI: 0.899-0.980), respectively, for global radial strain (GRS).

\section{Discussion}

In this study, we evaluated the clinical outcomes of idiopathic DCM patients with moderate to severe LV systolic dysfunction according to CMR-derived LV strain and 
Table 2 Baseline standard CMR-data and myocardial deformation parameters of patients with and without the primary outcome

\begin{tabular}{|c|c|c|c|c|}
\hline Parameters & All patients $(n=172)$ & $\begin{array}{l}\text { Patients without the primary } \\
\text { outcome }(n=129)\end{array}$ & $\begin{array}{l}\text { Patients with the primary } \\
\text { outcome }(n=43)\end{array}$ & $P$ value \\
\hline LV EF (\%) & $23.7 \pm 7.9$ & $23.6 \pm 8.0$ & $24.1 \pm 7.5$ & 0.675 \\
\hline LV EDV (ml) & $284.3 \pm 91.4$ & $279.2 \pm 81.5$ & $299.9 \pm 116.0$ & 0.199 \\
\hline LV ESV (ml) & $219.9 \pm 85.7$ & $215.5 \pm 76.4$ & $233.2 \pm 109.0$ & 0.242 \\
\hline Cardiac output (L/min) & $5.04 \pm 1.53$ & $4.95 \pm 1.51$ & $5.32 \pm 1.57$ & 0.166 \\
\hline Cardiac index $\left(\mathrm{L} / \mathrm{min} / \mathrm{m}^{2}\right)$ & $2.95 \pm 0.84$ & $2.89 \pm 0.82$ & $3.12 \pm 0.88$ & 0.114 \\
\hline RV EF (\%) & $41.2 \pm 17.0$ & $42.3 \pm 18.0$ & $37.7 \pm 12.8$ & 0.129 \\
\hline RV EDV (ml) & $145.6 \pm 60.7$ & $140.7 \pm 56.3$ & $160.3 \pm 70.9$ & 0.066 \\
\hline RV ESV (ml) & $91.6 \pm 56.7$ & $87.1 \pm 53.8$ & $105.1 \pm 63.3$ & 0.071 \\
\hline RV cardiac output (L/min) & $4.21 \pm 1.33$ & $4.14 \pm 1.23$ & $4.43 \pm 1.59$ & 0.227 \\
\hline Presence of LGE, n (\%) & $66(38.4)$ & $42(33.1)$ & $24(58.5)$ & 0.004 \\
\hline Myocardial mass (g) & $142.2 \pm 41.1$ & $144.1 \pm 43.6$ & $136.5 \pm 31.9$ & 0.232 \\
\hline Quantitative LGE mass (g) & $6.8 \pm 14.5$ & $5.6 \pm 13.3$ & $10.6 \pm 17.2$ & 0.093 \\
\hline LGE mass/LV myocardial mass (\%) & $4.7 \pm 9.5$ & $3.8 \pm 8.6$ & $7.4 \pm 11.5$ & 0.073 \\
\hline Global radial strain (\%) & $12.3 \pm 5.6$ & $12.5 \pm 5.6$ & $11.9 \pm 5.8$ & 0.563 \\
\hline Global circumferential strain (\%) & $-7.3 \pm 3.1$ & $-7.3 \pm 3.1$ & $-7.2 \pm 3.2$ & 0.869 \\
\hline Global longitudinal strain (\%) & $-7.1 \pm 2.9$ & $-7.2 \pm 2.9$ & $-6.9 \pm 2.7$ & 0.613 \\
\hline
\end{tabular}

Primary outcome: all-cause death, heart transplantation. Values are mean $\pm \mathrm{SD}, \mathrm{n}(\%)$

Abbreviations: $C M R$ cardiovascular magnetic resonance, EDV end-diastolic volume, $E F$, ejection fraction, ESV end-systolic volume, $L G E$ late gadolinium enhancement, $L V$ left ventricle, $R V$ right ventricle

LGE. Our major finding was that LV strain had no significant prognostic value in these high-risk patients while the presence of LGE was a significant predictor of adverse outcomes.

\section{Differential prognosis according to LV strain}

To the best of our knowledge, a study published by Buss et al. has been the only other study that evaluated the prognostic value of CMR-derived LV strain in the DCM population [24]. In contrast to our study, they found that CMR-derived LV longitudinal strain was an independent predictor of survival in DCM that offered incremental information for risk stratification beyond clinical parameters, biomarkers, and standard CMR. However, they included patients with various systolic functions, and the LV EF of their study population was $36.1 \pm 13.8 \%$, much higher than that in our study $(23.7 \pm 7.9 \%)$.

LV myocardial strain is inevitably related to LV EF, and it has been reported that LV EF is determined by global myocardial strain and myocardial thickness [29]. In our study, the Pearson correlation coefficients between LV EF and GLS, GCS, and GRS were - $0.733(P$ $<0.01),-0.780(P<0.01)$, and $0.739(P<0.01)$, respectively. LV EF was not associated with the outcomes in our study, as expected because all of our study patients had severely depressed LV EF. Likewise, it is not surprising that LV strain could not predict adverse outcomes because it is so closely related to LV EF.

\section{Differential prognosis according to LGE}

Regarding the differential clinical outcomes according to LGE, previous studies have well demonstrated this correlation in patients with DCM. It has been reported that presence of LGE was associated with adverse clinical outcomes such as cardiovascular death, hospitalization due to HF, and sudden death $[20-23,30]$. This study showed results similar to those of previous studies: the presence of LGE was the strong independent predictor for adverse outcomes. We also considered the quantitative extent of LGE, but the extent of LGE was not significantly related to clinical outcomes. The presence of LGE might thus be more important than the extent of LGE when predicting adverse outcomes.

\section{Limitations}

This study has some important limitations. First, there are inherent limitations in non-randomized comparisons, such as allocation bias, uneven distribution of risk factors, and the possibility of unmeasured confounders. Second, data regarding the cause of death such as cardiovascular death including pump failure and sudden cardiac death was not available. Third, the follow-up duration varied by individual 
Table 3 Univariate analysis of primary and secondary outcomes

\begin{tabular}{|c|c|c|c|c|c|c|}
\hline & Primar & & & Second & & \\
\hline & $H R$ & $95 \% \mathrm{Cl}$ & $P$ value & $H R$ & $95 \% \mathrm{Cl}$ & $P$ value \\
\hline Age (years) & 0.993 & $0.973-1.013$ & 0.487 & 0.991 & $0.970-1.011$ & 0.373 \\
\hline Male gender & 1.350 & $0.693-2.631$ & 0.378 & 0.726 & $0.388-1.361$ & 0.318 \\
\hline Mean arterial pressure $(\mathrm{mmHg})$ & 0.971 & $0.945-0.997$ & 0.028 & 0.959 & $0.931-0.986$ & 0.004 \\
\hline Hypertension & 1.257 & $0.663-2.384$ & 0.483 & 0.896 & $0.449-1.789$ & 0.756 \\
\hline Diabetes mellitus & 1.417 & $0.712-2.818$ & 0.321 & 1.387 & $0.679-2.833$ & 0.369 \\
\hline Dyslipidemia & 1.521 & $0.469-4.936$ & 0.485 & 0.945 & $0.228-3.917$ & 0.938 \\
\hline Current smoker & 0.978 & $0.474-2.017$ & 0.951 & 0.853 & $0.403-1.807$ & 0.678 \\
\hline Chronic kidney disease $^{a}$ & 1.660 & $0.813-3.389$ & 0.164 & 1.709 & $0.837-3.492$ & 0.141 \\
\hline Previous CVA & 3.501 & $1.079-11.362$ & 0.037 & 2.265 & $0.545-9.418$ & 0.261 \\
\hline Body mass index, $\mathrm{kg} / \mathrm{m}^{2}$ & 0.960 & $0.888-1.037$ & 0.298 & 0.936 & $0.858-1.021$ & 0.134 \\
\hline ECG at baseline & & & & & & \\
\hline Heart rate (bpm) & 1.000 & $0.984-1.015$ & 0.972 & 1.013 & $0.997-1.029$ & 0.109 \\
\hline Left bundle-branch block & 1.122 & $0.519-2.426$ & 0.770 & 1.580 & $0.774-3.224$ & 0.209 \\
\hline QRS duration (ms) & 1.005 & $0.995-1.015$ & 0.353 & 1.003 & $0.993-1.013$ & 0.598 \\
\hline Laboratory data & & & & & & \\
\hline Serum creatinine (mg/dl) & 2.249 & $0.784-6.455$ & 0.132 & 0.950 & $0.271-3.334$ & 0.950 \\
\hline $\mathrm{Na}(\mathrm{mmol} / \mathrm{l})$ & 0.810 & $0.751-0.875$ & $<0.001$ & 0.860 & $0.794-0.931$ & $<0.001$ \\
\hline In(NT-proBNP) (pg/ml) & 1.376 & $1.083-1.748$ & 0.009 & 1.519 & $1.190-1.939$ & 0.001 \\
\hline Cardiac medications & & & & & & \\
\hline Beta-blockers & 1.148 & $0.564-2.334$ & 0.704 & 0.767 & $0.396-1.486$ & 0.432 \\
\hline ACE-inhibitors/ARB & 1.492 & $0.531-4.192$ & 0.447 & 2.171 & $0.669-7.050$ & 0.197 \\
\hline Spironolactone & 1.100 & $0.588-2.056$ & 0.766 & 1.380 & $0.724-2.632$ & 0.328 \\
\hline Diuretics & 0.921 & $0.463-1.832$ & 0.814 & 1.732 & $0.767-3.914$ & 0.187 \\
\hline Digoxin & 1.658 & $0.847-3.242$ & 0.140 & 1.662 & $0.847-3.258$ & 0.140 \\
\hline LV EF (\%) & 1.006 & $0.969-1.044$ & 0.759 & 0.970 & $0.933-1.009$ & 0.132 \\
\hline LV EDV (ml) & 1.003 & $1.000-1.006$ & 0.093 & 1.003 & $1.000-1.006$ & 0.090 \\
\hline LV ESV (ml) & 1.003 & $0.999-1.006$ & 0.108 & 1.004 & $1.000-1.007$ & 0.041 \\
\hline Cardiac output (L/min) & 1.092 & $0.908-1.314$ & 0.349 & 0.961 & $0.784-1.177$ & 0.699 \\
\hline Cardiac index $\left(\mathrm{L} / \mathrm{min} / \mathrm{m}^{2}\right)$ & 1.228 & $0.868-1.738$ & 0.245 & 1.024 & $0.708-1.481$ & 0.901 \\
\hline RV EF (\%) & 0.984 & $0.964-1.005$ & 0.124 & 0.976 & $0.955-0.998$ & 0.033 \\
\hline RV EDV (ml) & 1.005 & $1.000-1.009$ & 0.041 & 1.004 & $0.999-1.009$ & 0.080 \\
\hline RV ESV (ml) & 1.005 & $1.000-1.009$ & 0.049 & 1.005 & $1.000-1.010$ & 0.045 \\
\hline RV stroke volume (ml) & 1.007 & $0.991-1.024$ & 0.376 & 0.995 & $0.977-1.012$ & 0.556 \\
\hline RV cardiac output (L/min) & 1.122 & $0.894-1.407$ & 0.320 & 0.962 & $0.759-1.220$ & 0.751 \\
\hline Presence of LGE & 2.277 & $1.221-4.246$ & 0.010 & 2.023 & $1.066-3.839$ & 0.031 \\
\hline Myocardial mass (g) & 0.997 & $0.990-1.005$ & 0.510 & 0.987 & $0.978-0.997$ & 0.008 \\
\hline Quantitative LGE mass (g) & 1.014 & $0.998-1.031$ & 0.086 & 1.009 & $0.990-1.028$ & 0.370 \\
\hline LGE mass/LV myocardial mass (\%) & 1.024 & $0.998-1.051$ & 0.068 & 1.018 & $0.989-1.047$ & 0.232 \\
\hline Global radial strain (\%) & 0.974 & $0.921-1.030$ & 0.363 & 0.955 & $0.901-1.013$ & 0.129 \\
\hline Global circumferential strain (\%) & 1.030 & $0.934-1.136$ & 0.554 & 1.062 & $0.963-1.172$ & 0.229 \\
\hline Global longitudinal strain (\%) & 1.048 & $0.945-1.163$ & 0.375 & 1.066 & $0.955-1.191$ & 0.254 \\
\hline
\end{tabular}

a Chronic kidney disease was defined as eGFR $<60 \mathrm{ml} / \mathrm{min} / 1.73 \mathrm{~m}^{2}$, calculated using the 4-component MDRD study equation

Abbreviations: $A C E$ angiotensin-converting-enzyme, $A R B$ angiotensin II receptor blockers, $B N P$ B-type natriuretic peptide, $C l$ confidence interval, $C V A$

cerebrovascular accident, $E C G$, electrocardiography, EDV end-diastolic volume, EF, ejection fraction, ESV, end-systolic volume, $H R$, hazard ratio, $L G E$ late gadolinium enhancement, $L V$, left ventricle, $R V$, right ventricle

patient. Next limitation was that those with several forms of reversible cardiomyopathies such as tachycardia induced cardiomyopathy or hypertensive heart failure were excluded. Furthermore, many patients were excluded from the analysis of LV strain. Since this might have resulted in selection bias, so the 


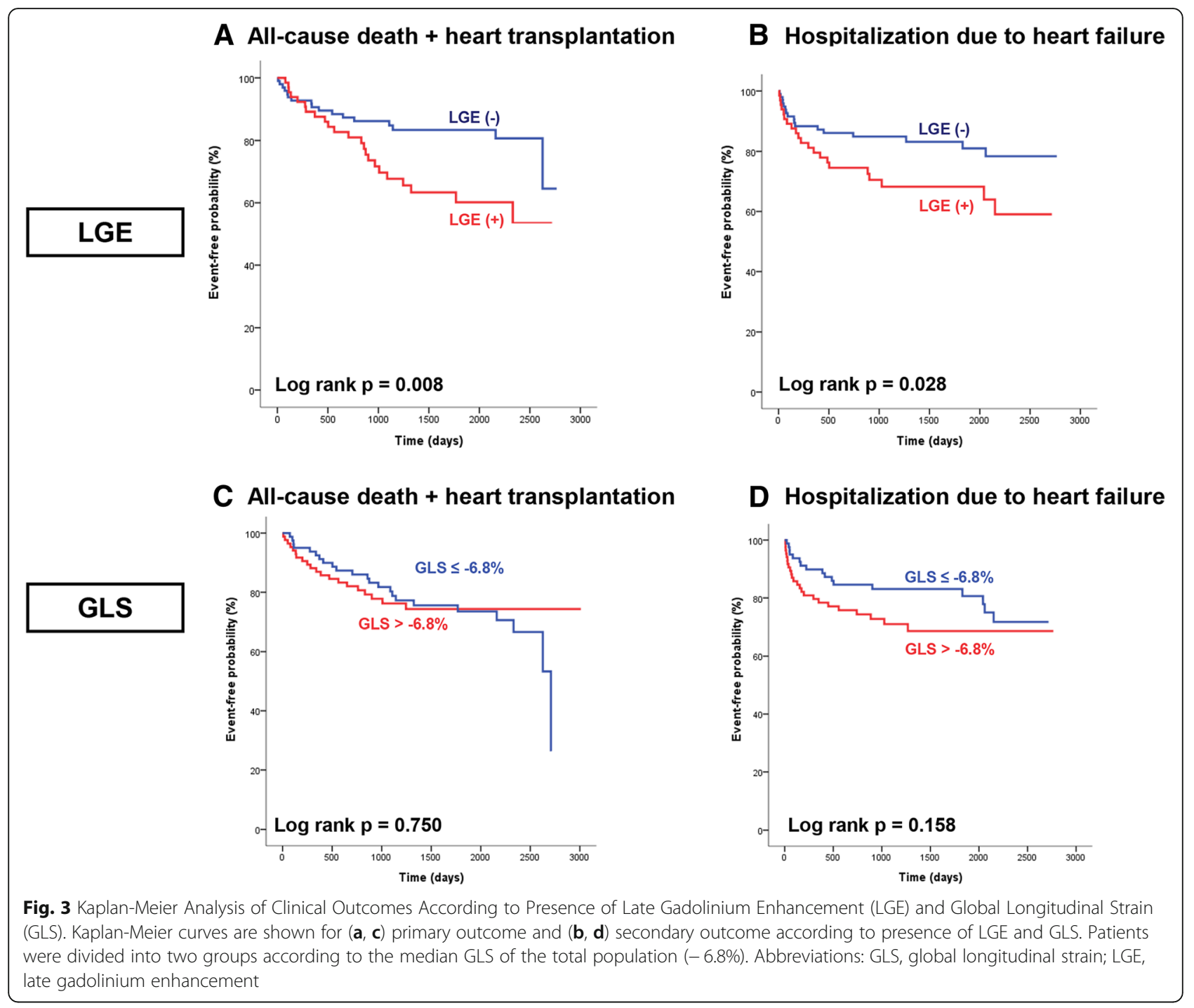

findings of our study would not be generalizable to the entire HF with reduced EF population. However, there was no difference in the presence of LGE which was one of main CMR variable between those who were included in the strain analysis and excluded patients. Thus the overall finding might be not affected. Lastly, HF management was not controlled; thus, our conclusions should not be extrapolated to all patients with idiopathic DCM. A further study with a prospective and multicenter design is required.

Table 4 Multivariable proportional-hazard model of primary and secondary outcomes

\begin{tabular}{|c|c|c|c|c|c|c|}
\hline & \multicolumn{3}{|c|}{ Primary outcome $e^{a}$} & \multicolumn{3}{|c|}{ Secondary outcome } \\
\hline & $H R$ & $95 \% \mathrm{Cl}$ & $P$ value & $H R$ & $95 \% \mathrm{Cl}$ & $P$ value \\
\hline $\mathrm{Na}(\mathrm{mmol} / \mathrm{l})$ & 0.821 & $0.761-0.885$ & $<0.001$ & 0.896 & $0.817-0.982$ & 0.019 \\
\hline Presence of LGE & 4.729 & $1.111-20.121$ & 0.0355 & 2.358 & $1.229-4.523$ & 0.010 \\
\hline Myocardial mass & & & & 0.986 & $0.975-0.996$ & 0.009 \\
\hline InNT-proBNP & & & & 1.352 & $1.031-1.771$ & 0.029 \\
\hline
\end{tabular}

${ }^{\mathrm{a}}$ Based on a multivariable Cox model with time-dependent covariates at 6 months. Before 6 months, the HR was $0.71(p$-value $=0.58,95 \% \mathrm{Cl}: 0.206,2.415)$, while after 6 months, the HR is as given in the Table

The Harrell's c-index of multivariable Cox proportional hazards model were 0.727 (95\% Cl: 0.616 to 0.838 ) and 0.744 (95\% Cl: 0.648 to 0.839 ) for primary and secondary outcomes, respectively

Abbreviations: NT-proBNP, N-terminal pro-B-type natriuretic peptide; Cl confidence interval, HR hazard ratio, LGE late gadolinium enhancement 


\section{Conclusions}

In idiopathic DCM patients with reduced EF, CMR LGE is a good predictor of adverse outcomes. LV strain, however, had no significant prognostic value in patients with moderate to severe systolic dysfunction. As our study was analyzed retrospectively and selection bias could not be excluded, further studies with prospective design are warranted to support our findings.

\section{Additional file}

Additional file 1: Table S1. Baseline characteristics between 172

included and 95 excluded patients. Table S2. Baseline standard

CMR-data between 172 included and 95 excluded patients. (PDF 149 kb)

\section{Abbreviations}

ACE: Angiotensin converting enzyme inhibitor; ARB: Angiotensin receptor blocker; CMR: Cardiovascular magnetic resonance; DCM: Dilated cardiomyopathy; EDV: End diastolic volume; EF: Ejection fraction; ESV: Endsystolic volume; GCS: Global circumferential strain; GLS: Global longitudinal strain; GRS: Global radial strain; HF: Heart failure; HR: Hazard ratio; LGE: Late gadolinium enhancement; LV: Left ventricle/Left ventricular; MAP: Mean arterial pressure; RV: Right ventricle/Right ventricular; SD: Standard deviation; sNA: Serum sodium

\section{Acknowledgements}

The authors thank Prof. Keumhee Carriere (Research Professor, Samsung Medical Center, and Professor of Statistics, Department of Mathematical and Statistical Sciences, University of Alberta, Canada) for providing statistical consultation.

\section{Availability of data and materials}

The datasets used and/or analysed during the current study are available from the corresponding author on reasonable request.

\section{Authors' contributions}

Each author contributed significantly to the submitted work: SHP and SMK contributed to data acquisition, analysis, and interpretation and drafted the manuscript. EKK, SAC, YHC, SCL, ESJ contributed to the data interpretation and edited the manuscript. JOC designed and coordinated the study, contributed to the data interpretation, and edited the manuscript. All authors read and approved the final manuscript.

\section{Ethics approval and consent to participate}

Ethical approval was obtained by the local Institutional Review Board of Samsung Medical Center (IRB File No. SMC 2017-01-104). All study subjects agreed to provide information for CMR cohort registry and written informed consent for this study was waived from our Institutional Review Board.

\section{Competing interests}

The authors declare that they have no competing interests.

\section{Publisher's Note}

Springer Nature remains neutral with regard to jurisdictional claims in published maps and institutional affiliations.

\section{Author details}

${ }^{1}$ Department of Internal Medicine, Heart Vascular Stroke Institute, Samsung Medical Center, Sungkyunkwan University School of Medicine, 81 Irwon-ro, Gangnam-gu, Seoul 06351, Republic of Korea. ${ }^{2}$ Department of Radiology, Cardiovascular Imaging Center, Samsung Medical Center, Sungkyunkwan University School of Medicine, Seoul, Republic of Korea.
Received: 11 October 2017 Accepted: 25 May 2018

Published online: 14 June 2018

\section{References}

1. Felker GM, Thompson RE, Hare JM, Hruban RH, Clemetson DE, Howard DL, et al. Underlying causes and long-term survival in patients with initially unexplained cardiomyopathy. N Engl J Med. 2000;342:1077-84.

2. Choi DJ, Han S, Jeon ES, Cho MC, Kim JJ, Yoo BS, et al. Characteristics, outcomes and predictors of long-term mortality for patients hospitalized for acute heart failure: a report from the korean heart failure registry. Korean Circ J. 2011:41:363-71.

3. Fuster V, Gersh BJ, Giuliani ER, Tajik AJ, Brandenburg RO, Frye RL. The natural history of idiopathic dilated cardiomyopathy. Am J Cardiol. 1981;47: $525-31$

4. Juilliere Y, Danchin N, Briancon S, Khalife K, Ethevenot G, Balaud A, et al. Dilated cardiomyopathy: long-term follow-up and predictors of survival. Int J Cardiol. 1988;21:269-77.

5. Maron BJ, Towbin JA, Thiene G, Antzelevitch C, Corrado D, Arnett D, et al. Contemporary definitions and classification of the cardiomyopathies: an American Heart Association scientific statement from the council on clinical cardiology, heart failure and transplantation committee; quality of care and outcomes research and functional genomics and translational biology interdisciplinary working groups; and council on epidemiology and prevention. Circulation. 2006:113:1807-16.

6. Curtis JP, Sokol SI, Wang Y, Rathore SS, Ko DT, Jadbabaie F, et al. The association of left ventricular ejection fraction, mortality, and cause of death in stable outpatients with heart failure. J Am Coll Cardiol. 2003;42:736-42.

7. Wang NC, Maggioni AP, Konstam MA, Zannad F, Krasa HB, Burnett JC Jr, et al. Clinical implications of QRS duration in patients hospitalized with worsening heart failure and reduced left ventricular ejection fraction. JAMA. 2008:299:2656-66.

8. Anand IS, Fisher LD, Chiang YT, Latini R, Masson S, Maggioni AP, et al. Changes in brain natriuretic peptide and norepinephrine over time and mortality and morbidity in the valsartan heart failure trial (Val-HeFT). Circulation. 2003:107:1278-83.

9. Miller WL, Hartman KA, Burritt MF, Grill DE, Rodeheffer RJ, Burnett JC Jr, et al. Serial biomarker measurements in ambulatory patients with chronic heart failure: the importance of change over time. Circulation. 2007;116:249-57.

10. Yusuf S, Pitt B, Davis CE, Hood WB, Cohn JN. Effect of enalapril on survival in patients with reduced left ventricular ejection fractions and congestive heart failure. N Engl J Med. 1991;325:293-302.

11. Yusuf S, Pitt B, Davis CE, Hood WB Jr, Cohn JN. Effect of enalapril on mortality and the development of heart failure in asymptomatic patients with reduced left ventricular ejection fractions. N Engl J Med. 1992;327:685-91.

12. Grayburn PA, Appleton CP, DeMaria AN, Greenberg B, Lowes B, Oh J, et al. Echocardiographic predictors of morbidity and mortality in patients with advanced heart failure. the Beta-blocker Evaluation of Survival Trial (BEST) J Am Coll Cardiol. 2005:45:1064-71.

13. Lee $\mathbf{W H}$, Packer M. Prognostic importance of serum sodium concentration and its modification by converting-enzyme inhibition in patients with severe chronic heart failure. Circulation. 1986;73:257-67.

14. Adams KF Jr, Dunlap SH, Sueta CA, Clarke SW, Patterson JH, Blauwet MB, et al. Relation between gender, etiology and survival in patients with symptomatic heart failure. J Am Coll Cardiol. 1996;28:1781-8.

15. Oh C, Chang HJ, Sung JM, Kim JY, Yang W, Shim J, et al. Prognostic estimation of advanced heart failure with low left ventricular ejection fraction and wide QRS interval. Korean Circ J. 2012;42:659-67.

16. Karamitsos TD, Francis JM, Myerson S, Selvanayagam JB, Neubauer S. The role of cardiovascular magnetic resonance imaging in heart failure. J Am Coll Cardiol. 2009:54:1407-24.

17. Gonzalez JA, Kramer CM. Role of imaging techniques for diagnosis, prognosis and Management of Heart Failure Patients: cardiac magnetic resonance. Curr Heart Fail Rep. 2015;12:276-83.

18. McCrohon JA, Moon JC, Prasad SK, McKenna WJ, Lorenz CH, Coats AJ, et al. Differentiation of heart failure related to dilated cardiomyopathy and coronary artery disease using gadolinium-enhanced cardiovascular magnetic resonance. Circulation. 2003;108:54-9.

19. Krittayaphong R, Boonyasirinant T, Saiviroonporn P, Udompunturak S. Late gadolinium enhancement from cardiac magnetic resonance in ischemic and non-ischemic cardiomyopathy. J Med Assoc Thail. 2011;94(Suppl 1):S33-8. 
20. Kuruvilla S, Adenaw N, Katwal AB, Lipinski MJ, Kramer CM, Salerno M. Late gadolinium enhancement on cardiac magnetic resonance predicts adverse cardiovascular outcomes in nonischemic cardiomyopathy: a systematic review and meta-analysis. Circ Cardiovasc Imaging. 2014;7:250-8.

21. Gulati A, Jabbour A, Ismail TF, Guha K, Khwaja J, Raza S, et al. Association of fibrosis with mortality and sudden cardiac death in patients with nonischemic dilated cardiomyopathy. JAMA. 2013;309:896-908.

22. Lehrke S, Lossnitzer D, Schob M, Steen H, Merten C, Kemmling H, et al. Use of cardiovascular magnetic resonance for risk stratification in chronic heart failure: prognostic value of late gadolinium enhancement in patients with non-ischaemic dilated cardiomyopathy. Heart. 2011;97:727-32.

23. Wu KC, Weiss RG, Thiemann DR, Kitagawa K, Schmidt A, Dalal D, et al. Late gadolinium enhancement by cardiovascular magnetic resonance heralds an adverse prognosis in nonischemic cardiomyopathy. J Am Coll Cardiol. 2008:51:2414-21.

24. Buss SJ, Breuninger K, Lehrke S, Voss A, Galuschky C, Lossnitzer D, et al. Assessment of myocardial deformation with cardiac magnetic resonance strain imaging improves risk stratification in patients with dilated cardiomyopathy. Eur Heart J Cardiovasc Imaging. 2015;16:307-15.

25. Richardson P, McKenna W, Bristow M, Maisch B, Mautner B, O'Connell J, et al. Report of the 1995 World Health Organization/international society and Federation of Cardiology Task Force on the definition and classification of cardiomyopathies. Circulation. 1996;93:841-2.

26. Liu T, Ma X, Liu W, Ling S, Zhao L, Xu L, et al. Late gadolinium enhancement amount as an independent risk factor for the incidence of adverse cardiovascular events in patients with stage $\mathrm{C}$ or D heart failure. Front Physiol. 2016;7:484.

27. Maron MS. Contrast-enhanced CMR in HCM: what lies behind the bright light of LGE and why it now matters. JACC Cardiovasc Imaging. 2013;6:597-9.

28. Lee JM, Rhee TM, Hahn JY, Hwang D, Park J, Park KW, et al. Comparison of outcomes after treatment of in-stent restenosis using newer generation drugeluting stents versus drug-eluting balloon: patient-level pooled analysis of Korean multicenter in-stent restenosis registry. Int J Cardiol. 2017;230:181-90.

29. Maclver $\mathrm{DH}$, Adeniran I, Zhang $\mathrm{H}$. Left ventricular ejection fraction is determined by both global myocardial strain and wall thickness. IJC Heart \& Vasculature. 2015;7:113-8.

30. Assomull RG, Prasad SK, Lyne J, Smith G, Burman ED, Khan M, et al. Cardiovascular magnetic resonance, fibrosis, and prognosis in dilated cardiomyopathy. J Am Coll Cardiol. 2006;48:1977-85.

\section{Ready to submit your research? Choose BMC and benefit from:}

- fast, convenient online submission

- thorough peer review by experienced researchers in your field

- rapid publication on acceptance

- support for research data, including large and complex data types

- gold Open Access which fosters wider collaboration and increased citations - maximum visibility for your research: over $100 \mathrm{M}$ website views per year

At BMC, research is always in progress.

Learn more biomedcentral.com/submissions 